\title{
A Cross Sectional Study of Kretek Smoking in Indonesia as a Major Risk to Public Health
}

\author{
Krishna Palipudi ${ }^{1}$, Lazarous Mbulo ${ }^{1 *}$, Soewarte Kosen ${ }^{2}$, Aditama Tjandra ${ }^{2}$, \\ Kadarmanto $^{3}$, Farukh Qureshi ${ }^{4}$, Linda Andes ${ }^{1}$, Dhirendra N Sinha ${ }^{5}$, Samira \\ Asma $^{1}$
}

\begin{abstract}
Background: Tobacco smoking is a major cause of preventable disease and death worldwide. Kreteks are clove-flavored cigarettes made from a combination of tobacco and ground-clove mixed with a sauce, smoked widely in Indonesia. Because health and social consequences of kretek smoking are potentially as great as those of traditional cigarettes, this study examines the prevalence of kretek smoking in Indonesia and associated risk factors. Materials and Methods: The study used nationally representative Indonesia Global Adult Tobacco Survey data. Multiple logistic regression analysis was employed to identify correlates of kretek smoking. Results: Onethird of Indonesian adults smoked tobacco of which about $90.0 \%$ smoked kreteks. Prevalence of kretek smoking among men $(60.9 \%)$ was more than 25 times the rate among women $(2.3 \%)$. Overall, the highest prevalence of kretek use was in the age group 45-54 years (36.5\%), followed by 34-44 (35.1\%), 25-34 (34.2 \%), and 55-64 years $(\mathbf{3 2 . 8 \%})$. By wealth index, prevalence of kreteks smoking among those in the middle index was almost $50 \%$ above the rate for the wealthiest group (36.4\% vs $24.8 \%$ respectively). Logistic regression results showed that being male, being older, having less education, and being less wealthy were significant predictors of kretek smoking, while urban vs rural residence was not. Conclusions: Kretek smoking is common in Indonesia and is entrenched in the sociocultural fabric of the country. However, potential consequences of kretek smoking, particularly as risks for noncommunicable diseases, underscore the importance of a comprehensive approach to tobacco control as outlined in the World Health Organization's MPOWER strategies.
\end{abstract}

Keywords: Kreteks - clove cigarettes - smoking - Indonesia - tobacco control

Asian Pac J Cancer Prev, 16 (16), 6883-6888

\section{Introduction}

Tobacco use is a major cause of preventable deaths worldwide, and its use is increasing in numerous low- and middle-income countries, including Indonesia (World Health Organization, 2008). Tobacco kills an estimated 6 million people each year and leaves many others suffering from debilitating diseases (Mathers and Loncar, 2006). Countries which, have a better understanding of how tobacco is used within their borders, and develop effective interventions in tobacco control and prevention accordingly, stand a better chance to reduce the impact of the tobacco epidemic and ultimately reverse its course.

Indonesia is home to 246.9 million people (United Nations, 2013) and is a major producer and consumer of tobacco (Barber et al., 2008). Tobacco use in Indonesia is particularly high among males, and kreteks are the most popular tobacco product in the country (Barber et al., 2008;
World Health Organization, Regional Office for South East Asia, 2012). Smoking rates increased from 27.0\% in 1995 to $34.4 \%$ in 2004 , reflecting the effects of low tobacco prices, increasing income, and the mechanization of the kretek industry since the 1970s (Barber et al., 2008). In recent years, Indonesia has had to contend with the increased presence of transnational tobacco companies that have entered the kretek market, resulting in the intensification of tobacco advertising, promotion, and sponsorship (Lawrence and Collin, 2004).

Kreteks are cigarettes that are made of a combination of tobacco and ground clove mixed with special flavorings called "sauces," which are unique to each brand (Arnez, 2009; Malson, 2003). The clove and the sauce combine to give kreteks an aroma that is markedly different from that of traditional cigarettes (Malson, 2003). Kreteks, also sometimes referred to as clove cigarettes, have a long history of use in Indonesia, as they were created by

${ }^{I}$ Global Tobacco Control Branch, Office on Smoking and Health, National Center for Chronic Disease Prevention and Health Promotion, CDC, Atlanta, Georgia, US, ${ }^{2}$ National Institute of Health Research \& Development, Republic of Indonesia, ${ }^{3}$ Badan Pusat Statistik, ${ }^{4}$ Country Office, World Health Organization, Jakarta, Indonesia, ${ }^{5}$ South-East Asia Regional Office, World Health Organization, New Delhi, India*For correspondence: gou8@cdc.gov,vyp7@cdc.gov 
a resident of that country during the 1800s (Arnez, 2009; Hanusz, 2000). Originally designed to deliver clove to the lungs to relieve chest pain and asthma, kreteks quickly gained broad popularity in Indonesia and began being sold internationally (Hanusz, 2000; Arnez, 2009).

Like all tobacco products, kreteks have serious health consequences for both users and those exposed to their secondhand smoke (Prignot, et al., 2008). In addition to possessing the hazards of conventional cigarettes, the chemical constituents of clove could also pose additional health risks (Malson, 2003; WHO International Agency for Research on Cancer, 1985). In a study of 33 brands of Indonesian clove cigarettes, Polzin and colleagues found that every brand they tested contained eugenol, and that some brands contained anethole and coumarin, all in highly variable concentrations (Polzin et al., 2007). Eugenol has been classified as a possible human carcinogen (WHO International Agency for Research on Cancer, 1985) and could be more detrimental to pulmonary tissues than other major constituents of kreteks (Polzin et al., 2007). It also has anesthetic properties that allow smokers to tolerate higher concentrations of total particulate matter, or tar (Hurt, Ebbert, Achadi and Croghan, 2012). Similar to eugenole, coumarin and anethole are found in conventional cigarettes at a lower level, and present health risks when inhaled in high levels (Polzin et al., 2007).

Recently a series of studies have conducted a toxicological assessment of kretek cigarettes in comparison to an American blended cigarette (Piadé et al., 2013; Roemer, Dempsey, Schorp, 2014). The findings showed that there was no increased hazard potential of kreteks compared to the American blended cigarette. However, they acknowledge that kreteks cigarettes were still as dangerous for health as the American blended cigarette.

Given the health effects associated with kreteks and the large number of Indonesian adults who smoke them, kretek smoking carries a significant health burden in Indonesia. In 2008, it was estimated that overall smoking prevalence was $34 \%$, and that $63 \%$ of males were smokers. Of the 57 million smokers in Indonesia, about half were projected to die of tobacco-related illnesses (Barber et al., 2008).

To address the effects of Indonesia's tobacco epidemic and, ultimately, to reverse its course through targeted interventions, it is important to understand kretek use and the factors that may influence it. Although tobacco use in the country has been assessed several times in the past decade (Statistics Indonesia - Badan Pusat Statistik and Macro International, 2008), there is limited information at the national level on the proportion of the population that smokes kreteks. In the Demographic and Health Survey 2007 (Statistics Indonesia - Badan Pusat Statistik and Macro International, 2008), the use of kreteks was not distinguished from the use of other types of cigarettes. In addition, the survey only covered ever-married women and currently married men aged $15-49$ years.

The implementation of the Indonesia Global Adult Tobacco Survey (GATS) in 2011 was a significant step toward the provision of information enabling a better understanding of the use of tobacco products in the country. The purpose of this paper is to analyze the prevalence of kretek smoking among adults aged 15 years or older and the factors associated with kretek use in the country. The paper also explores existing best practices that could be adopted to address high kretek smoking prevalence to prevent potential health consequences.

\section{Materials and Methods}

\section{Data}

GATS data from Indonesia was collected in 2011 through a household survey; a standardized, consistent protocol was employed to collect and analyze the data (Pujari et al., 2012; Palipudi et al., 2013).

The survey used a multistage cluster sample design, and the data was weighted and post-stratified to represent the national adult population. Details of the survey methodology are available elsewhere (World Health Organization, Regional Office for South East Asia, 2012).

\section{Measurement}

Kretek use was determined by two questions. First, tobacco smoking in general was determined by asking respondents, "Do you currently smoke tobacco on a daily basis, less than daily, or not at all?" Second, smoking of different types of tobacco products was assessed by the question, "On average, how many of the following products do you currently smoke each day? Also let me know if you smoke the product, but not every day". If respondents did not use the product every day, they were asked, "How many of the following do you currently smoke during a usual week?" Respondents were asked about seven different types of tobacco products, including manufactured white cigarettes, hand-rolled cigarettes, kreteks, and three other types of smoked tobacco, which were later merged into an "other smoked tobacco" category. Kretek users were those that currently smoked tobacco on a daily or less-than-daily basis and currently smoked one or more kreteks during a usual week.

The demographic variables in the analysis were gender (male/female), age group (15-24, 25-34, 35-44, 45-54, $55-64,65+$ ), residence (urban/rural), education, and an asset-based wealth index. Education was grouped into four categories that ranged from no formal education/ less than primary education to college/university graduate or above. The wealth index was based on

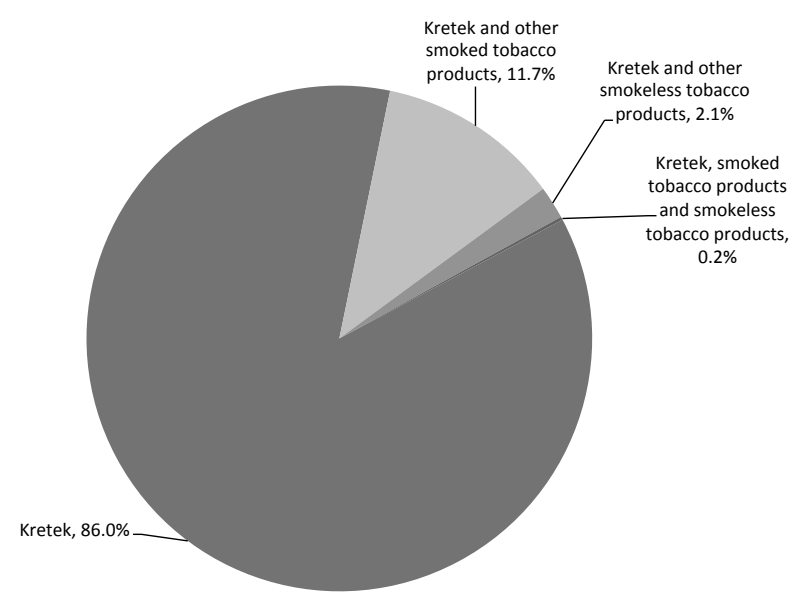

Figure 1. Tobacco use among Kretek Smokers 


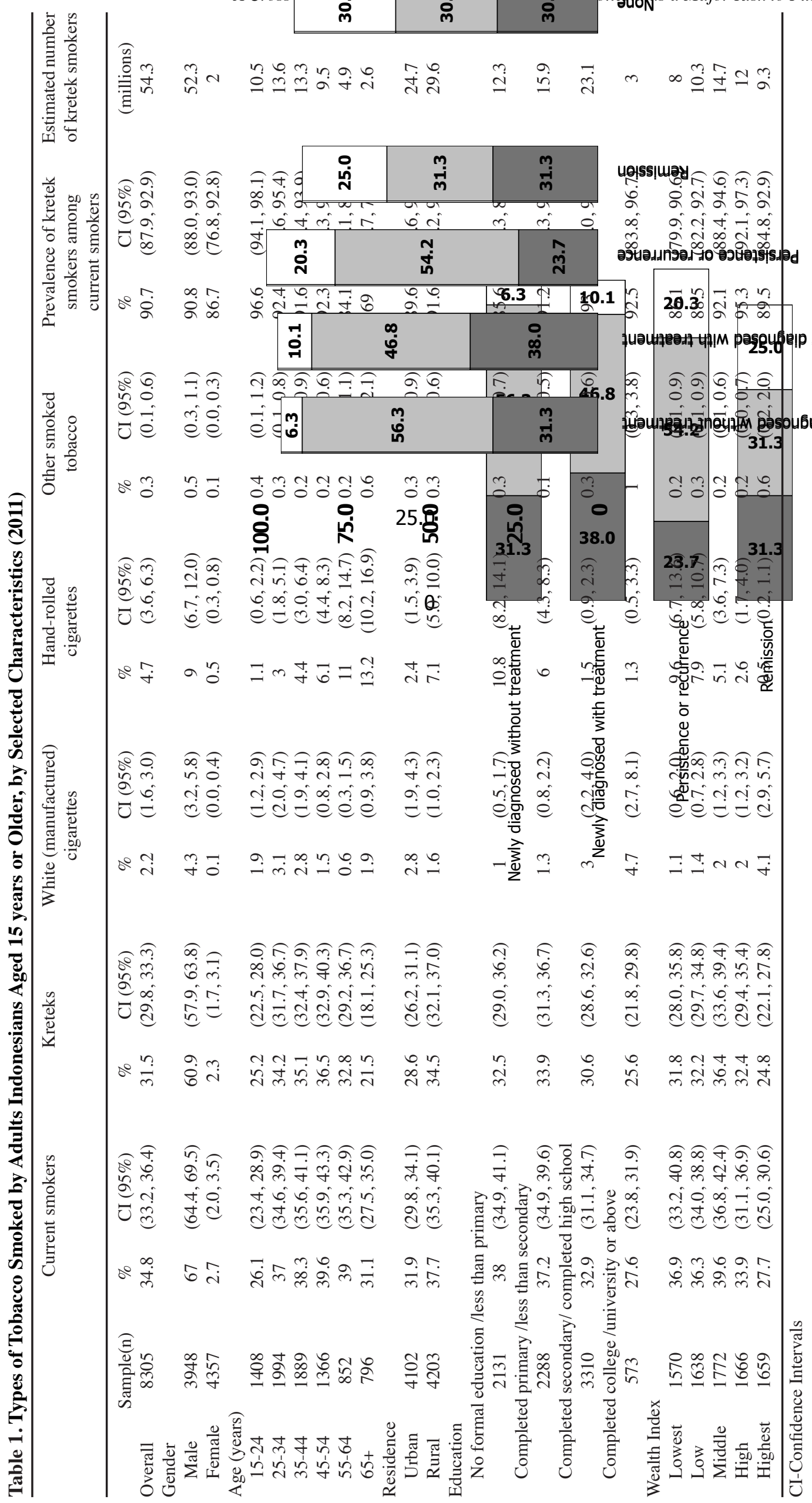


Krishna Palipudi et al

household assets such as electricity, flush toilet, fixed telephone, cell telephone, television, radio, refrigerator, car, moped/scooter/motorcycle, washing machine, and so forth. Respondents were divided into wealth quintiles ranking from one (lowest) to five (highest) and, thus, approximately $20 \%$ of respondents were in each quintile. Details on the computation of this index can be found elsewhere (Palipudi et al., 2012).

\section{Analysis}

SPSS ${ }^{\circledR}$ version 18.0 for complex samples (SPSS Inc., Chicago, IL) was employed for the data analysis, which included descriptive statistics and a multivariate logistic regression analysis for estimating the correlates of kretek use. The dependent variable was given a value of " 1 " if a respondent was a current kretek user and " 0 " if the respondent was a nonsmoker. The logistic regression model was used to calculate the predicted probabilities of kretek smoking at specific values of a key factor, holding all other factors constant.

\section{Results}

Estimates for the percentage of Indonesian adults who were current tobacco smokers in 2011 and the type of tobacco products they smoked are presented in Table 1. Overall, $34.8 \%$ of Indonesian adults were current tobacco smokers, and the prevalence among males was 25 times that of females $(67.0 \%$ vs $2.7 \%$, respectively). The great majority $(90.7 \%)$ of current tobacco smokers smoked kreteks, a figure that translates to approximately 54.3 million kretek smokers in Indonesia. Among all kretek smokers, $86.0 \%$ used kreteks only, $11.7 \%$ were dual users of kreteks and other smoked tobacco products, and $2.1 \%$ were dual users of kreteks and smokeless tobacco (figure 1).

The prevalence of kretek use was significantly lower in the oldest and youngest age groups than it was among those aged 25-34, 34-44, 45-54, or 55-64 years (Table 1). By level of educational attainment, prevalence was lowest among those with at least a college or university education, but the difference in prevalence between that group and others was significant for only the second level (completed primary/less than secondary). By wealth category, the highest index had a significantly lower prevalence of kretek smoking than did any of the other categories.

\section{Predictors of kretek smoking}

Of the five independent variables included in the multiple logistic regression analysis (gender, age, urban $v s$ rural residence, education level, and wealth index level), all but residence were significantly associated with the use of kreteks (table 2). Being male showed a highly significant association with kretek smoking $(\mathrm{p}<0.001)$, as did being in any group aged 25 years or older in comparison with the 15-24 group ( $\mathrm{p}<0.001$ for all age groups). After controlling for age, residence, education, and wealth, the predicted probability of kretek smoking among males was $74.1 \%$. Mean predicted probabilities of being a kretek smoker were $43.4 \%$ for those aged $55-64$ years, $45.5 \%$ for those aged $45-54$, and $42.1 \%$ for those
Table 2. Predictors of Kretek Smoking among Adult Indonesians (2011): Results from a Logistic Regression Model

\begin{tabular}{|c|c|c|c|}
\hline \multirow[t]{2}{*}{ Characteristic } & \multicolumn{2}{|c|}{$\begin{array}{l}\text { Kretek smokers } \\
\text { vs never smokers }\end{array}$} & \multirow[t]{2}{*}{$\begin{array}{l}\text { Predicted } \\
\text { probability }\end{array}$} \\
\hline & OR & $95 \% \mathrm{CI}$ & \\
\hline \multicolumn{4}{|l|}{ Gender } \\
\hline Male & 202.8 & $(140.5,292.8)^{*}$ & 0.741 \\
\hline Female & 1 & & 0.024 \\
\hline \multicolumn{4}{|l|}{ Age (years) } \\
\hline $15-24$ & 1 & & 0.272 \\
\hline $25-34$ & 3.27 & $(2.6,4.1)^{*}$ & 0.391 \\
\hline $35-44$ & 3.06 & $(2.3,4.0)^{*}$ & 0.421 \\
\hline $45-54$ & 4.41 & $(3.0,6.4)^{*}$ & 0.455 \\
\hline $55-64$ & 3.31 & $(2.2,5.0)^{*}$ & 0.434 \\
\hline $65+$ & 2.56 & $(1.5,4.4)^{*}$ & 0.384 \\
\hline \multicolumn{4}{|l|}{ Residence } \\
\hline Rural & 0.79 & $(0.6,1.1)$ & 0.354 \\
\hline Urban & 1 & & 0.41 \\
\hline \multicolumn{4}{|c|}{ Education } \\
\hline \multicolumn{4}{|c|}{ No formal education//less than primary } \\
\hline & 3.84 & $(2.4,6.2)^{*}$ & 0.412 \\
\hline \multicolumn{4}{|c|}{ Completed primary/less than secondary } \\
\hline & 2.33 & $(1.6,3.5)^{*}$ & 0.407 \\
\hline \multicolumn{4}{|c|}{ Complete secondary/completed high school } \\
\hline & 1.4 & $(1.0,1.9) \dagger$ & 0.359 \\
\hline \multicolumn{4}{|c|}{ Complete college/university or above } \\
\hline & 1 & & 0.332 \\
\hline \multicolumn{4}{|l|}{ Wealth index } \\
\hline Lowest & 1.53 & $(1.0,2.2) \dagger$ & 0.386 \\
\hline Low & 1.46 & $(1.1,2.0) \dagger$ & 0.391 \\
\hline Middle & 1.74 & $(1.3,2.4)^{*}$ & 0.432 \\
\hline High & 1.25 & $(0.9,1.7)$ & 0.375 \\
\hline Highest & 1 & & 0.323 \\
\hline
\end{tabular}

aged 35-44 years.

People with no formal education or less than a primary education, those who completed a primary but not a secondary education, and those who had completed a secondary education but not college or university were significantly more likely to use kreteks than those with a college or university education. The mean predicted probability of being a kretek smoker was $41.2 \%$ among those with no formal education or less than a primary education, and $40.7 \%$ among those with a primary education but less than a secondary education. Similarly, those in the bottom three categories of wealth status (lowest, low, middle) were significantly more likely to smoke kreteks than those with the highest wealth status. The mean predicted probability of being a kretek smoker was $43.2 \%$ among those in the middle wealth category, $39.1 \%$ in the low wealth category, and $38.6 \%$ in the lowest wealth category. No significant association with place of residence was found when we accounted for gender, age, education, and wealth index.

\section{Discussion}

Two notable conclusions can be drawn from this study: more than one-third of Indonesian adults (persons aged 15 years or older) smoke kreteks, and the great majority of current smokers use this tobacco product. The very high 
estimate $(90.7 \%)$ for the prevalence of kretek smoking among all smokers, representing an estimated 54.3 million smokers of kreteks within Indonesia, indicates that Indonesia alone has more kretek smokers than smokers in neighboring countries Malaysia, (WHO Regional Office for South East Asia, 2012) Thailand, (WHO Regional Office of South East Asia, 2011) and Viet Nam (Ministry of Health of Viet Nam, 2010) combined. Thus, kretek smoking reflects a major public health risk for Indonesia.

Consistent with other studies (Barraclough, 1999; Barber et al., 2008; Arnez, 2009), this study found that the prevalence of kretek smoking was also particularly high among men in Indonesia, defining tobacco use as a predominantly male behavior. This pattern reflects the country's history and culture, where social norms disapprove of women taking up smoking, but where smoking has traditionally been considered culturally appropriate for men (Barraclugh, 1999; Ngi et al., 2007; Arnez, 2009). Nonetheless, while active kretek smoking tends to be limited to men, children and women are likely to be exposed to secondhand smoke and may affect their health including the health of the unborn fetuses for pregnant women (WHO South East Asia Regional Office, 2009; WHO, 2010a). Although Kaufman et al. (2014) and Nichter et al. (2010) found a shift towards disapproval of smoking in public places in their study in Bogor and Palembang cities, Indonesia, they also found that people were hesitant to enforce the smoke-free policies when it came to asking men of status and/or community leaders to stop smoking.

Our results demonstrate the widespread use of kretek cigarettes in Indonesia and, as such, are consistent with previous findings indicating that kretek smoking is embedded in Indonesia's social and cultural norms, raising a significant public health challenge. As smoking is one of the major preventable causes of noncommunicable diseases (NCDs) (WHO, 2010b), curbing kretek smoking could significantly contribute to reducing and preventing the incidence of NCDs among Indonesians, thus helping to alleviate the tobacco-related disease burden in the country. Addressing kretek smoking, particularly among men, would be critical to reducing deaths related to NCDs in Indonesia.

Given the health burden posed by NCDs and the deep cultural roots of kretek smoking in Indonesia, addressing this health behavior as a best practice require a comprehensive approach targeting not only smoking behavior but also environmental factors that may support the behavior. Such a comprehensive approach would include interventions that address the social normative acceptance of smoking and not merely revising existing policies, but introducing a new policy framework and accompanying regulatory measures (California Department of Health/Tobacco Control Section, 1998).

A social normative change approach would allow for the creation of an environment and a legal framework that would influence current and potential smokers by making smoking less desirable, less acceptable, and less accessible (California Department of Health/Tobacco Control Section, 1998). To generate a social normative change, Indonesia may consider the adoption of the World
Health Organization's (WHO) MPOWER strategy, a technical package made up of six tobacco control measures of proven cost-effectiveness that include monitoring tobacco use and prevention policies; protecting people from secondhand smoke; offering help with quitting; warning against the dangers of tobacco; enforcing bans on tobacco advertising, promotion, and sponsorship; and raising tobacco products taxes (WHO, 2003)

Indonesia has already begun to implement some of the MPOWER measures. The government has taken steps to simplify the tobacco products tax structure and introduced graphic health warnings on cigarette packages in 2013 which are important tobacco control measures (Health Ministry of the Republic of Indonesia 2013). In addition, the country is a party to the 2008 Resolution of the WHO South-East Asia Regional Committee that emphasized the need to strengthen national tobacco control programs and urged countries to adopt the MPOWER policy package to effectively implement the WHO Framework Convention on Tobacco Control (WHO, Regional Office for South East Asia 2008). In addition, as observed by Kaufman, Merritt, Rimbatmaja and Cohen (2014), there is already an increasing willingness among Indonesians in cities such as Bogor and Palembang cities to ask people not to smoke in public places.

The steps that Indonesia implemented as described above and adoption of the full MPOWER package could give the country a strong basis for successfully reversing its tobacco epidemic, including the impact of NCDs. MPOWER measures would, for example, provide Indonesia with the tools needed to prevent both smoking initiation and the transition to dependence on tobacco among young people. As our findings showed, kretek use was lower among the youngest age group than among all age groups except those aged 65 years or older, which may indicate a transition period to dependence among the youngest group. MPOWER measures, which include banning tobacco advertising, promotion, and sponsorship, as well as increasing tobacco products taxes, have been found to be effective in preventing smoking initiation and promoting cessation (Badaer, Boisclair and Ferrence, 2011; Jha and Chaloupka, 1999; Esson and Leeder, 2004).

Furthermore, adopting the MPOWER strategy could allow Indonesia to address tobacco-related social and economic disparities. As has been observed elsewhere (Palipudi et al., 2012) our study found that kretek smoking was more common among people in the lower socioeconomic status (SES) quintiles than among those in higher SES quintiles. MPOWER measures adopted by other countries may offer Indonesia an opportunity to effectively prevent and reduce kretek smoking among its low-SES population (Jha and Chaloupka, 1999). For example, higher tobacco taxes have been observed to be effective in preventing initiation among young people and in reducing use, particularly among low-SES populations (Jha and Chaloupka, 1999).

Continuous monitoring of tobacco use is needed to further understand the tobacco epidemic in Indonesia, and the present study contributes to that effort. Also, the monitoring of tobacco use is an important part of the MPOWER strategy and provides a basis for tobacco 
control and prevention.

A limitation of the present study might be that it relied on self-reported data. Such data may introduce biases from respondents because of problems such as inaccurate recall or a desire to give socially acceptable answers. A second limitation might be that the results are estimates of tobacco use behavior among Indonesians aged 15 years or older only, but this seems to be, at best, a minor concern.

\section{Disclaimer}

The findings and conclusions in this report are those of the authors and do not necessarily represent the official position of CDC or GATS partner organizations.

\section{Funding}

This research received no specific grant from any funding agency in the public, commercial or not-for-profit sectors. However, GATS was supported by the Bloomberg Philanthropies' Initiative to Reduce Tobacco Use.

\section{References}

Arnez M (2009). Tobacco and kretek: Indonesian drugs in historical change. Austrian Journal of South-East Asian Studies, 2, 49-69.

Bader P, Boisclair D, Ferrence R (2011). Effects of tobacco taxation and pricing on smoking behavior in high risk populations: a knowledge synthesis. Int J Environ Res Public Health, 8 , 4118-39.

Barber S, Adioetomo SM, Ahsan A, et al (2008). Tobacco economics in Indonesia. Paris: international union against tuberculosis and lung disease.

Barraclough S (1999). Women and tobacco in Indonesia. Tob Control, 8, 327-32.

Hanusz M (2000). Kretek: The culture and heritage of indonesia's clove cigarettes. tortola, british virgin islands, equinox publishing.

California Department of Health/Tobacco Control Section (1998). A model for change. the california experience in tobacco control. sacramento, California Department of Health.

Esson KM, Leeder SR (2004). The Millennium development goals and tobacco control: an opportunity for global partnership. Geneva, World Health Organization.

Health Ministry of the Republic of Indonesia (2013). Regulation of the Health Minister of the Republic of Indonesia Number 28 of 2013 concerning imprinting of health warnings and health information on tobacco product packaging. Unofficial translation. Available at http://www.tobaccocontrollaws.org/ files/live/Indonesia/Indonesia\%20-\%20MoH\%20Decree\%20 No.\%2028\%20of\%202013.pdf

Hurt RD, Ebbert JO, Achadi A, Croghan IT (2012). Roadmap to a tobacco epidemic: transnational tobacco companies invade Indonesia. Tob Control, 21, 306-12.

Institute for Public Health (2012). Report of the Global Adult Tobacco Survey (GATS) Malaysia, 2011. Kuala Lumpur, Malaysia, Ministry of Health Malaysia, 2012.

Jha P, Chaloupka FJ (1999). Curbing the epidemic: governments and the economics of tobacco control. Washington, World Bank.

Kaufman MR, Merritt AP, Rimbatmaja R, Cohen JE (2014). 'Excuse me, sire. Please don't smoke here'. A qualitative study of social enforcement of smoke-free policies in Indonesia. Health Policy and Planning, 1-8.

Lawrence S, Collin J (2004). Competing with kreteks: transnational tobacco companies, globalisation, and Indonesia. Tob Control, 13 96-103.

Malson JL, Lee EM, Murty R, et al (2003). Clove cigarette smoking: biochemical, physiological, and subjective effects. Pharmacol Biochem Behav, 74, 739-45.

Mathers CD, Loncar D (2006). Projections of global mortality and burden of disease from 2002 to 2030. PLoS Medicine, 3, 442.

Ministry of Health of Viet Nam (2010). Global Adult Tobacco Survey (GATS) Viet Nam. Hanoi, Ministry of Health.

Nichter M, Nichter M, Pamawati RS, Ng N (2010). Developing a smoke free household initiative: an Indonesian case study. Acta Obstet Gynecol Scand, 89, 578-81.

Ngi N, Weinhall L, Ohman A. (2007)“'If I don't smoke, I'm not a real man-Indonesian boys' views about smoking." Health Educ Res, 22, 794-804.

Palipudi KM, Gupta PC, Sinha DN, et al (2012). GATS Collaborative Group. Social determinants of health and tobacco use in thirteen low and middle income countries: evidence from Global Adult Tobacco Survey. PLoS One, 7, 33466.

Palipudi KM, Morton J, Hsia J, et al (2013). Methodology of the Global Adult Tobacco Survey -- 2008-2010. Global Health Promotion, 16, 1757-9.

Piadé JJ, Roemer, E, Dempsey R, et al (2014). Toxicological assessment of kretek cigarettes: Part 2: Kretek and Americanblended cigarettes, smoke chemistry and in vitro toxicity. Re gul Toxicol Pharm, 70, 15-25.

Polzin GM, Stanfill SB, Brown CR, et al (2007). Determination of eugenol, anethole, and coumarin in the mainstream cigarette smoke of Indonesian clove cigarettes. Food Chem Toxicol, 45, 1948-53.

Prignot JJ, Sasco AJ, Poulet E, et al (2008). Alternative forms of tobacco use. Int J Tuberc Lung Dis, 12, 718-27.

Pujari SJ, Palipudi KM, Morton J, et al (2012). Electronic data collection and management system for global adult tobacco survey. J Public Health Inform, 4, 1-20.

Roemer E, Dempsey R, Schorp MK (2014). Toxocology assessment of kretek cigarettes: Part 1: Background, assessment approach, and summary of findings. Regul Toxicol Pharm, 70, 2-14.

Statistics Indonesia (Badan Pusat Statistik BPS) and Macro International (2008). Demographic and Health Survey 2007. Calverton, MD: BPS and Macro International.

United Nations (2013). World Population Prospects: The 2012 Revision: Volume I: Comprehensive Tables. United Nations, New York.

WHO (2003). Framework Convention on Tobacco Control. Geneva, World Health Organisation.

WHO (2010a). Gender, women, and the tobacco epidemic. Geneva, WHO

WHO (2010b). Global status report on noncommunicable diseases 2010. Geneva, WHO

World Health Organization (2008). WHO report on the global tobacco epidemic, 2008: the MPOWER package. Geneva, WHO.

WHO International Agency for Research on Cancer (1985). IARC Monographs on the evaluation of the carcinogenic risk of chemicals to humans: tobacco habits other than smoking; Betel-Quid and Areca-Nut chewing; and some elated nitrosamines. Vol. 37. Lyon, IARC.

World Health Organization, Regional Office for South East Asia (2012). Global adult tobacco survey: Indonesia Report 2011. Jakarta, Indonesian Ministry of Health.

WHO Regional Office for South East Asia (2011). Global adult tobacco survey: Thailand report. Nonthaburi, Thailand, Thailand Ministry of Health.

WHO South East Asia Regional Office (2009). Indonesia (Ages 13-15) Global Youth Tobacco Survey (GYTS) 2009. FACT SHEET. Available at http://www.searo.who.int/entity/ noncommunicable_diseases/data/ino_gyts_fs_2009.pdf

WHO, Regional Office for South East Asia (2008). Resolution of the WHO regional committee for South East Asia. SEA/ RC61/R4 Tobacco control. Regionalcommittee meeting 61 New Delhi, India, 8-11. 